\title{
MORAR NO EXTREMO SUL DE SÃO PAULO: SOCIEDADE E NATUREZA NA REGIÃO DA GUARAPIRANGA EM MEADOS DO SÉCULO 20
}

\author{
LIVING IN THE FAR SOUTH OF SÃO PAULO: SOCIETY AND \\ NATURE IN THE REGION OF GUARAPIRANGA IN THE \\ MIDDLE OF THE 20TH CENTURY
}

Janes Jorge ${ }^{1, *}$ (D)

\begin{abstract}
RESUMO: O objetivo do artigo é problematizar o avanço da urbanização no extremo sul da cidade de São Paulo, especificamente na região da represa do Guarapiranga, em meados do século XX, a partir da experiência dos moradores com o mundo natural. A lenta conquista de infraestrutura e serviços urbanos básicos, tensões sociais e posições ambíguas diante da natureza marcam esse processo histórico ainda hoje inconcluso.
\end{abstract}

Palavras-chave: São Paulo. Guarapiranga. Urbanização. Meio ambiente.

\begin{abstract}
This article aims to discuss the urbanization advance in the extreme south of São Paulo city, specifically in Guarapiranga water dam region, during midst of twentieth century, based on residents' experience related to natural environment. The slow conquest of infrastructure and basic urban services, social tensions, and ambiguous positions regarding nature marked this historical process still unfinished today.
\end{abstract}

Keywords: São Paulo. Guarapiranga. Urbanization. Environment.

\footnotetext{
1.Universidade Federal de São Paulo - Escola de Filosofia, Letras e Ciências Humanas - Departamento de História - Guarulhos (SP), Brasil.

*Autor correspondente: janes.jorge@unifesp.br

Dossiê organizado por: Carmen Lucia Soares e Heloísa Helena Pimenta Rocha
} 


\section{Um Processo Histórico Secular e Tenso}

Desde fins do século XIX até os dias atuais, o município de São Paulo assiste à expansão da mancha urbana sobre a zona rural ou áreas naturais. Secular, tal processo provocou, e ainda provoca, o encontro entre moradores que buscam seu lugar na cidade e florestas, campos e várzeas ou propriedades agropastoris de tamanho variado. Esses encontros apresentaram características diversas ao longo do tempo e da região em que ocorreram e constituem capítulo fundamental da história ambiental de São Paulo; na verdade, de toda a Bacia Hidrográfica do Alto Tietê.

A expressão "tudo aqui era mato" e outras semelhantes que são observadas nos registros que documentam essa frente de expansão da metrópole, frente majoritariamente constituída pelas classes populares, indicam, no mais das vezes, as dificuldades em morar nesse ambiente outro que surgia, marcado por todo tipo de carência e a lenta conquista de infraestrutura e serviços urbanos mínimos. O "mato" era a negação da cidade e, portanto, algo a ser superado. Contudo as fontes históricas também apresentam a valorização da natureza por parte dos moradores, indicando um horizonte investigativo mais complexo e ambíguo para quem se interessa por essa história ainda pouco conhecida. Morar no extremo da fronteira urbana era viver ao ar livre e aprender a lidar com o mundo natural no cotidiano, ambos em rápida transformação. O objetivo deste artigo é refletir sobre tal fenômeno na Zona Sul da cidade de São Paulo, mais especificamente na região da represa do Guarapiranga. A relação dos moradores com as águas da represa, objeto de outros dois textos que escrevi (JORGE, 2015, 2016), não é o foco do artigo, que irá centrar-se em outros elementos do mundo natural.

\section{A Ocupação do Extremo Sul da Região de São Paulo}

A região sul do atual município de São Paulo, com matas e rios, é marcada por duas grandes represas: a do Rio Guarapiranga e a represa do Rio Grande (Billings), construídas nas primeiras décadas do século XX para compor o parque hidrelétrico da São Paulo Railway Light and Power Company e paulatinamente incorporadas ao sistema público de abastecimento de água, tendo suas bacias se transformado em área de proteção de mananciais. Quando de sua construção, essas represas faziam parte da cidade de Santo Amaro, que, em 1935, foi anexada à capital paulista. O represamento do Guarapiranga, finalizado em 1908, produziu um dos lugares mais belos e aprazíveis da região de São Paulo. O imenso lago era cercado por floresta densa, entremeada por pequenos trechos de várzea especialmente na embocadura de córregos que nela desaguavam. Esse encanto natural criado a partir da ação humana foi registrado por Prado Júnior (1966), em meados do século passado, dessa forma:

Mas não são apenas [...] fatores econômicos que provocaram e provocam o povoamento e utilização pelo homem deste semideserto que circunda a cidade. O fator diversão tem também o seu papel, e de vulto. Chácaras particulares de recreio, parques e pontos de diversão, para onde a população paulistana converge nos dias de folga, já tomaram tal vulto que transformaram a paisagem local e não podem escapar à observação do geógrafo. De todos os arredores da capital, é Santo Amaro que se tornou centro de atração por excelência desta atividade recreativa. Favoreceu sem dúvida o imenso lago que forma aí a barragem e represa construída como um suplemento de energia para o consumo da cidade, duplicada hoje por esta nova represa a que me referi noutra parte do trabalho, que se prolonga até o alto 
da Serra, servindo para desviar as águas da bacia do Tietê para o mar, serra abaixo. São Paulo, longe do mar, e dispondo apenas de um rio pouco atraente como é o Tietê, encontrou nestas represas um sucedâneo que na falta de melhor foi avidamente aproveitado. Santo Amaro, em particular, às margens das represas transformou-se completamente; e hoje os parques, jardins pomares e plantações de luxo, cercando habitações às vezes magníficas, cobrem em boa parte toda esta região (PRADO JÚNIOR, 1966, p. 135).

Mesmo antes que a represa ficasse pronta projetava-se a ocupação do seu entorno por moradores ricos de São Paulo. Os anúncios dos jornais paulistanos indicam essa atividade mercantil que transformou a região de Santo Amaro.

Futurosa aplicação de capital. Vende-se em Santo Amaro, entre a moderníssima Inter-Lagos e o Clube de Campo, uma magnífica propriedade com 240000 m.q. Lugar aprazível, com belíssima vista para a represa, possuindo duas ótimas residências e outras benfeitorias. Uma aplicação de capital das mais vantajosas pela segurança da sua valorização em cada dia que passa. Preço e outros detalhes com Assis, rua São Bento, 45, 50, sala 501 (O ESTADO..., 1939, p. 19).

O incremento dos meios de transportes articulou-se a esse movimento, com a linha de bondes implantada pela companhia Light e, depois de 1929, uma estrada de rodagem, que ligava a cidade de São Paulo a Santo Amaro - estrada construída pela empresa S/A Auto-Estradas, que ambicionava implementar negócios imobiliários na região (MENDES; CARVALHO, 2000). Analisando a estruturação da Região Metropolitana de São Paulo, Juergen Richard Langenbuch notou que a "recreação campestre" ensejou em São Paulo um grande movimento especulativo no mercado de terras sobretudo a partir dos anos 1950:

Loteamentos de chácaras recreativas surgiram em toda parte, alicerçados em hábeis campanhas publicitárias. Tais loteamentos, em grande parte, surgiram em áreas que já encerravam a função de recreação campestre. Entre estas despontam as margens das represas Guarapiranga e Billings (ex Rio Grande). Em vistas da já avultada valorização fundiária, os loteamentos aqui se compõem de lotes muito pequenos, apresentando dimensões apenas um pouco superiores às normalmente encerradas pelos congêneres de fins residenciais (LANGENBUCH, 1971, p. 247).

Apesar do avanço da ocupação destinada a moradores das classes sociais privilegiadas, nas quais a relação com a natureza era valorizada, no final da década de 1940, a região da Guarapiranga acolheu um bairro destinado principalmente aos funcionários do setor público e da Light, em terras adquiridas junto à empresa Auto-Estradas S.A. Essa empresa possuía grandes planos para a região: o "Projeto Interlagos". Planejava a abertura das avenidas, a venda do terreno do aeroporto de Congonhas ao governo estadual, a implementação da Cidade Satélite Balneária de Interlagos, um loteamento para moradores de alto poder aquisitivo, mas que teria também funções comerciais e industriais; a construção de um autódromo (o de Interlagos), de uma igreja matriz e de um grande hotel na principal praia da represa. A igreja e o hotel, entretanto, nunca foram construídos, e o autódromo de Interlagos foi vendido para a prefeitura de São Paulo em 1954, quando a Auto-Estradas enfrentou dificuldades financeiras (MENDES; CARVALHO, 2000). 
A maior difusão dos automóveis a partir dos anos 1950, em especial dos ônibus e lotações, favorecia a expansão urbana rumo aos extremos da cidade. Eles passaram a ocupar um espaço cada vez mais importante nos deslocamentos dos moradores, ainda mais com o avanço da indústria automobilística no país e o abandono do transporte sobre trilhos e fluvial. Os veículos sobre pneus possuíam mais mobilidade que os trens e bondes, que exigiam trilhos e, no caso dos últimos, também eletricidade. Assim, moradores de localidades distantes dos trilhos podiam sonhar com a chegada do transporte coletivo na forma de ônibus oficiais ou clandestinos, ou mesmo com o carro particular. Com isso, os loteamentos periféricos ganhavam um estímulo a mais.

Cidade Dutra foi um conjunto residencial construído pela Caixa de Aposentadorias e Pensões de Serviços Públicos em São Paulo, depois transformada em Instituto de Aposentadorias e Pensões dos Ferroviários e Empregados em Serviços Públicos, em 1950. A partir dele se originou o bairro que, em 1964, tinha 15 mil habitantes, no cálculo orgulhoso de um jornal local, contando com:

[...] água encanada, luz, esgoto, serviço de ônibus, escolas primárias e secundárias, uma Sociedade de Amigos de Interlagos (SAI), Ambulatório Médico, Hospital de Interlagos, Postos de Puericultura, farmácia, dentistas, cinema, sociedades esportivas, comércio em ascensão contínua e templos religiosos dos quais o mais antigo é a capela de São Pancrácio, erigida em 1952 (HISTÓRICO..., 1964, p. 1).

Tal orgulho se justificava, da perspectiva dos moradores, pois foram muito difíceis os anos iniciais do bairro isolado em meio a uma vasta zona rural e áreas verdes. Um dos primeiros habitantes a se mudar para Cidade Dutra, em 29 de dezembro de 1949, recorda que dois caminhões pararam "superlotados de tarecos em frente a casa de número 338 na R. Guaiúba”. Estava acompanhado de dois parentes que vinham ajudá-lo no descarregamento da mudança. "Duas horas depois, os motoristas e seus ajudantes retornavam à Capital: antes porém tecerem elogios ao novo morador pela coragem de vir morar, com a esposa e dois filhos menores, numa localidade tão distante e carecedora de todo conforto". Uma moradora, por sua vez, recordava as palavras do sogro para o recém-esposo "você tem coragem de levar essa menina para aquele mato?", ao que ela respondeu: "Não se preocupe, pois eu nasci no mato" (HISTÓRICO..., 1965, p. 1; LEMBRANDO..., 1990, p. 3).

O que as palavras da esposa significavam? Que ela teria vindo da zona rural ou de outro bairro popular de São Paulo? Seja como for, a afirmação enfatizava que ela não se assustava com a região de sua nova casa, que poderia ser o que realmente sentisse, mas também uma frase dita para tranquilizar o pai do marido, preocupado com a vida no extremo sul, em um período em que a cidade, em áreas centrais, conhecia uma vida urbana plena, com infraestrutura e serviços urbanos consolidados e a multiplicação dos edifícios verticais, inclusive para uso residencial (ATIQUE, 2005).

Nos anos 1950, os jornais locais procuravam demonstrar otimismo com o avanço da ocupação da Guarapiranga. Ressaltavam que já havia uma estrada de asfalto que ligava "Cidade Dutra a Rio Bonito, Parelheiros, Cipó e Colônia, uma das zonas mais promissoras do município, prometendo grande desenvolvimento; é a chamada 'boca do sertão' do sul paulista” (DOMINGO..., 1959, p. 1). Um recémconstruído ramal da Estrada de Ferro Sorocabana atravessou Santo Amaro e a região da Guarapiranga, em demanda ao porto de Santos. Inicialmente estava planejada uma estação na Vila de São José,

[...] a fim de servir Interlagos, Cidade Dutra e Rio Bonito. Devido os protestos da população e sua real conveniência e utilidade, foi essa estação transferida para as proximidades de Cidade Dutra, atrás da pista de Interlagos, onde está prestando grandes e melhores serviços. 
Cidade Dutra é ponto final da linha de subúrbio (7 no total diariamente) que serve a região. Para Santos passam diariamente dois trens, e aos sábados e domingos há composições especiais, além do "Ouro Branco" (DOMINGO..., 1959, p. 4).

Quadros autorizou a desapropriação de um amplo terreno em frente ao autódromo para “a instalação de máquinas e instalações necessárias a abastecimento de água dos bairros de Cidade Dutra, Interlagos e adjacências", sendo que havia sido providenciado também "o crédito destinado a instalação da rede de iluminação pública para Cidade Dutra” (DOMINGO..., 1959, p. 1, 4). Jânio Quadros construiu sua carreira política tendo como base eleitoral os bairros periféricos de São Paulo. Quando prefeito, concedeu ampla anistia aos loteamentos irregulares, que puderam assim receber benfeitorias do poder público, em especial guias, sarjetas, pavimentação e luz elétrica. Em 1950, elegeu-se governador e ampliou em $50 \%$ a rede pública de abastecimento de água e em cinco vezes a adução para atender aos bairros da periferia (ROLNIK, 1997). Mais da metade da água vinha da Guarapiranga em 1956 (JORGE, 2015).

Maria Ferraz da Silva, que foi morar em Cidade Dutra em 1950, lamentou os primeiros tempos em que viveu em um lugar sem infraestrutura e serviços urbanos: "No início foi duro. A água vinha lá do Autódromo, vinha muito pouquinho, era suja, às vezes não vinha. A luz era que nem uma brasinha. Nem tinha quase condução. Tinha um ônibus que saia pela manhã e outro que voltava à tarde, quem perdia, perdia" (PREFEITURA DO MUNICÍPIO DE SÃO PAULO, 2004a, p. 4).

Contudo, se foi difícil, havia a vantagem de se evitar o pagamento do aluguel, mesmo que a casa de um dormitório fosse pequena para ela, seus pais e mais três irmãos. A ocupação da bacia do Guarapiranga compunha um quadro maior em que a população era empurrada cada vez mais para os extremos da cidade. Por toda São Paulo, a zona rural cedia lugar aos loteamentos urbanos, pois a procura por moradia era intensa. A situação era agravada e ficava fora de controle devido à ausência de uma política oficial de construção massiva de habitação popular. Contudo, se em Cidade Dutra e no bairro adjacente de Socorro a ocupação possuía um grau mínimo de planejamento e infraestrutura, nas demais áreas ao redor da represa, a ocupação se daria de outra forma, precária, como em outras partes da cidade. Fugindo do aluguel, levas de trabalhadores partiam em busca da periferia, onde compravam um lote e construíam suas casas como fosse possível. (MARCONDES,1999).

A autoconstrução periférica ganhou impulso após a Segunda Guerra Mundial. Entre 1940 e 1950, aproximadamente 100 mil famílias (ou cerca de 500 mil pessoas) passaram a morar em casas próprias nos extremos da cidade. Na década de 1960, as periferias das zonas leste, noroeste e sul de Santo Amaro tiveram um crescimento populacional ao redor de $13 \%$ ao ano e respondiam por $43 \%$ do crescimento demográfico, enquanto os bairros centrais cresceram por volta de $1 \%$. Nos anos 1970 e 1980, a tendência foi mantida, embora o ritmo de crescimento dos bairros periféricos tenha sido menor. Entre 1991 e 2000, a taxa média anual de crescimento da população de São Paulo ficou abaixo de 0,9\%, mas a periferia cresceu a níveis bastante superiores à média da cidade (ROLNIK, 2004).

Em Grajaú, as lembranças dos moradores antigos assinalam também a lenta transição do rural para o urbano. José da Paixão chegou à região para trabalhar na agricultura:

Aqui era a colônia japonesa. Antigamente era só agricultura, lavoura, granja. A gente trabalhava atrás de máquina o dia inteirinho. E pra catar batata não era tanto sofrimento. Era bom, era divertido. Você via a máquina passar, jogando pra trás, aquilo ficava branquinho na terra, você ia catando (PREFEITURA DO MUNICÍPIO DE SÃO PAULO, 2004b, p. 5). 
João Vitalino, pernambucano morador do bairro há 35 anos, registrou que:

Aqui era um sapé, um mato e lavoura. E a Granja Onoda, onde a população de Santo Amaro vinha comprar galinha. Aqui era tudo uma roça de mandioca e milho. Quando veio o loteador, foi fazendo os piquetinhos, dividindo as roças e vendendo para o pessoal. Não tinha asfalto, banco, não tinha a Robert Kennedy, a Teotônio Vilela. Era só mato, mineração de areia, a represa, seis ônibus, mais nada (PREFEITURA DO MUNICÍPIO DE SÃO PAULO, 2004b, p. 5).

Benedito Dias Ramos ficou famoso no bairro de Três Corações, que ele criou, em homenagem a sua cidade natal de Minas Gerais. Sua viúva, Dona América, contava que o primeiro terreno que ele comprou foi por volta de 1958 e depois foi comprando outros:

A intenção dele era fazer um sítio, mas aí apareceram pessoas interessadas em comprar lotes grandes para fazer casas. Porque ali era bonito, sabe? Lembro de muito mato, muito bicho. Então ele pensou que, se fosse vender, ele queria fazer lotes pequenos para quem não tinha muita condição (PREFEITURA DO MUNICÍPIO DE SÃO PAULO, 2004b, p. 5).

Em 1965, uma publicação local afirmava que moradores de Cidade Dutra "vem compreendendo a pouco e pouco que nosso bairro é uma realidade demográfica e que conseguimos em apenas quinze anos uma expressão de força política e social que outros bairros, com muitos anos ainda de existência não conseguiram" (O ANIVERSÁRIO..., 1965, p. 1). Como se nota, ainda havia dúvidas entre os próprios moradores, quanto à viabilidade do bairro, e o mesmo devia ocorrer nas localidades adjacentes, ainda menos urbanizadas. Espedito Barbosa Neves, contratado para fazer o desmatamento e aplainar a área em 1937 e 1938, contou que, mesmo com as facilidades de pagamento, ninguém queria comprar casas na região, porque "diziam que aqui era terra de índio", parecia "uma cidade fantasma" (ESPEDITO..., 1990, p. 1).

\section{Morar em Meio à Natureza}

Sílvio de Oliveira da Silva, ao lembrar a Cidade Dutra dos anos 1950, apontava "que tudo em volta era Eucalipto, tinha ar puro. Um tio meu veio pra cá se curar da bronquite asmática. O lazer era a Represa do Guarapiranga, eu aprendi a nadar lá”. Cleide Tosso recordava ir para Parelheiros por um caminho de terra, "locais totalmente verdes. A gente colhia frutas na beiradinha da Avenida Teotônio Vilela” (PREFEITURA DO MUNICÍPIO DE SÃO PAULO, 2004a, p. 4-5).

Como não ver nessas lembranças de 2004 a negação da cidade do início do século XX, a experiência dos moradores com um ambiente urbano hostil e a crise ambiental amplamente divulgada nos veículos de comunicação? A Avenida Teotônio Vilela do início do século, a mais importante via de transporte de toda margem direita da Guarapiranga, era marcada pelo trânsito intenso de automóveis, que cruzavam um bairro totalmente urbanizado. Ao ressaltar o ar puro, perfumado realmente pela presença dos eucaliptos fica evidente o contraste com o ar com cheiro da fumaça solta pelos escapamentos de carros e ônibus barulhentos e perigosos, pois causadores de vários tipos de acidentes; congestionados nessa antiga estrada, uma sinergia perversa que tornava o local insalubre e desagradável para os pedestres, ainda mais se fossem idosos. 
Na menção aos eucaliptos, a marca de que o território da Guarapiranga se transformara com a presença humana, antes mesmo do avanço urbano. Essa árvore australiana era muito valorizada na São Paulo de então. Muitas vezes era plantada em regiões alagadiças, em brejos, de forma que pudesse drenar o terreno, ou ao menos diminuir a umidade. Ocupava o lugar das espécies nativas. Por outro lado, as árvores frutíferas poderiam ser nativas ou não. Em meados do século XX, para muitos moradores, a abundância de áreas verdes e recursos naturais trazia alguma compensação ao fato de habitarem um lugar carente e distante dos principais centros urbanos de São Paulo. Se em algumas partes da cidade a densidade urbana era alta e não havia parques ou áreas verdes por perto, no extremo sul era o oposto. A vida ao ar livre decorria do próprio fato de ali se morar e as próprias atividades cotidianas, por exemplo ir e voltar ao trabalho, já implicavam no contato com plantas e bichos.

Na região do Jardim São Luis e Jardim Ângela, margem esquerda da represa, do lado oposto de Cidade Dutra, as lembranças são parecidas com as da margem direita. Elza Lopes da Silva Santos afirma que, ao se mudar, "Só tinha duas casas [...] a água era de poço e o dono da marcenaria [...] puxou o bico de luz pra gente". José Geraldo lembra que “onde eu moro tinha um buraco que a gente tomava banho. Tinha lambari, saracura, preá, tudo aqui nessa região. A diversão da gente, fim de tarde e época de calor era tomar banho lá e correr atrás dos passarinhos”. Já Lindaura Helfstein ressalta as festas juninas, "a folia de Reis, vinham em casa, entravam, a gente dava as coisas" (PREFEITURA DO MUNICÍPIO DE SÃO PAULO, 2004a, p. 5). Mais uma vez o que se vê é o encontro do urbano com o rural e seus costumes, com a fauna nativa. Encontro que, se era prazeroso para os moradores, acabava se transformando em mortal para os animais, pois a caça era corriqueira.

\section{O Início de um Novo Período}

Em 1964, um golpe de Estado instaurou uma ditadura no Brasil, que promoveu censura, torturas e assassinatos. Entre 1968 e 1973, o país atingiu altos níveis de crescimento econômico, acompanhados de forte concentração da riqueza, em um momento em que a população urbana do país já ultrapassava a rural. A pobreza se multiplicava nas cidades. Em 1975, um estudo que se transformou no livro São Paulo 1975, crescimento e pobreza, informava que na "Grande São Paulo", entre "1940 e 1950 a taxa de mortalidade infantil diminuiu de $30 \%$ e na década seguinte decresceu de $32 \%$, contrastando com os últimos 13 anos em que aumentou de 45\%". O estudo afirmava ainda que 80\% dos empréstimos do Banco Nacional da Habitação - criado em 1964 com o objetivo de "fazer de cada brasileiro o proprietário de sua casa" - foram "canalizados para as camadas médias e altas, ao mesmo tempo em que naufragavam os poucos planos habitacionais voltados para as camadas de baixo poder aquisitivo" (CAMARGO; ARNS, 1982, p. 47).

No extremo sul, as mudanças eram sentidas. Em 1972, o periódico local Noticiário pedia mais policiamento, uma delegacia de polícia, já que as ocorrências no bairro eram registradas em Cidade Ademar, um posto de saúde, pois era preciso utilizar o de Santo Amaro, e, principalmente, a melhoria no transporte coletivo "já que a empresa que monopoliza a linha é deficiente, não atendendo mais a tão numerosa população que é de cerca de 80.000 habitantes, e além de Cidade Dutra serve Rio Bonito - Jardim Primavera e Parque Santana". Para tanto, um grupo de moradores havia organizado uma comissão e enviado às autoridades municipais e estaduais ofícios e abaixo-assinados pedindo providências. O Noticiário concluía que iria aumentar "a população dessa área, pois já estão devastando as áreas verdes que circundam a represa para construírem cerca de 300 casas, e, por enquanto o 
Conjunto Residencial da BOHAB [sic] em Bororé, não está habitado” (CIDADE..., 1972, p. 2).

Por essa época, o bairro de Cidade Dutra ressentia-se também de obras viárias, em especial a extensão da Avenida Atlântica, que ladeava a margem esquerda da Guarapiranga, avenida que era "o principal cartão de visita da importante região turística de Santo Amaro”. Segundo o jornal de bairro, levando-se "em conta a enorme movimentação de veículos que demandam a região, particularmente nos feriados e fins-de-semana, dado o elevado número de clubes e chácaras ali existentes, é de extrema necessidade a ligação com a Estrada de Parelheiros e Clube de Campo” (ACONTECE..., 1975, p. 3).

A redemocratização do país, conquistada nos anos 1980, deu-se em meio à grave crise social e econômica, a maior herança da ditadura de 1964. Em São Paulo, assistia-se ao aumento do desemprego e à precarização das condições de trabalho, que, somados à ausência de uma política urbana capaz de priorizar a habitação popular, acentuaram os problemas de moradia. Nas últimas décadas do século 20, São Paulo assistiu a um renascimento dos cortiços na região central, à expansão das favelas, que eram raras até a década de 1960, e ao aumento das ocupações por movimentos de sem-teto. Em 1973, $1,09 \%$ da população de São Paulo vivia em favelas, percentual que em 1978 chegou a 4,01\% e não parou de crescer. Em 2004, os paulistanos que moravam em favelas eram 1.160.590, ou 11,12\% da população da cidade, com uma taxa de crescimento anual de 2,97\% (VILLAÇA, 2004). Grande parte dessas favelas se encontrava na bacia do Guarapiranga.

Nos 1970 e 1980, ao mesmo tempo que aumentavam as preocupações com a qualidade das águas da Guarapiranga e com o abastecimento de toda região metropolitana de São Paulo, a região de Santo Amaro se consolidava como importante polo industrial e a expansão urbana e populacional para a zona sul ganhava impulso. A marginal do Rio Pinheiros havia sido construída e o metrô chegava à cidade com a linha Norte-Sul. Sueli Chescon, moradora da região do jardim São Luis, lembrava que "o que trouxe muitos moradores para o bairro foi a Semp Toshiba, a Walita, a Wap e a Gradiente" (PREFEITURA DO MUNICÍPIO DE SÃO PAULO, 2004c, p. 5). No final dos anos 1980, haveria ainda a duplicação da estrada de Parelheiros, rebatizada como Teotônio Vilela e melhorias na rodovia Régis Bittencourt. Na região da Guarapiranga, havia bairros com infraestrutura urbana, em especial transporte público, que funcionavam como exemplo e referência para os moradores das ocupações que surgiam.

Cada vez mais, a instalação de loteamentos populares na bacia do Guarapiranga se fazia à margem de qualquer legislação, surgindo grandes aglomerações precárias, muitas vezes em encostas íngremes desmatadas, que ficavam sujeitas, portanto, a deslizamentos e à erosão que ajudava a assorear córregos e a própria represa. A ausência de saneamento na região adoecia os moradores e degradava ainda mais a natureza. A história de como esses moradores se relacionavam com o mundo natural ainda está por ser escrita.

\section{REFERÊNCIAS}

ACONTECE nos bairros. Ïnternotícias, 15 a 30 abr. 1975.

ATIQUE, F. Ensinando a morar: o Edifício Esther e os embates pela habitação vertical em São Paulo (19301962). Risco: Revista de Pesquisa em Arquitetura e Urbanismo (Online), n. 2, p. 38-55, 2005. https://doi. org/10.11606/issn.1984-4506.v0i2p38-55

CAMARGO, C. P. F.; ARNS, P. E. São Paulo, 1975, crescimento e pobreza. São Paulo: Loyola, 1982. 
CIDADE Dutra Aguarda Providências. Noticiário, jun. 1972.

DOMINGO último Cidade Dutra Comemorou 10 de existência. A Tribuna, Santos, 31 jan. 1959.

ESPEDITO: um desbravador. Gazeta de Santo Amaro, São Paulo, 25 jan. 1990.

HISTÓRICO da Cidade Dutra. O Interlagos, São Paulo, n. 3, jan. 1965.

HISTÓRICO da Cidade Dutra. Viva o Nosso Bairro. O Interlagos, São Paulo, n. 1, nov. 1964.

JORGE, J. A represa do Guarapiranga e os esportes na região de São Paulo (1905-1963). In: SOARES, C. L. (Org.). Uma educação pela natureza: A vida ao ar livre, o corpo e a ordem urbana. Campinas: Autores Associados, 2016.

JORGE, J. Guarapiranga: de represa combatida a patrimônio ambiental, 1906-2006. In: Cidades Paulistas: Estudos de História Ambiental Urbana. São Paulo: Alameda/FAPESP, 2015.

LANGENBUCH, J. R. A Estruturação da Grande São Paulo: Estudo de Geografia Urbana. Rio de Janeiro: IBGE, 1971.

MENDES, D.; CARVALHO, M. C. W. A Ocupação da Bacia do Guarapiranga: Perspectiva HistóricoUrbanística. In: FRANÇA, E.; FILARDO JUNIOR, A. S. (Colabs.). Guarapiranga: recuperação urbana e ambiental no Município de São Paulo. São Paulo: M. Carrilho Arquitetos, 2000.

LEMBRANDO velhos tempos. Gazeta de Santo Amaro, São Paulo, 11 nov. 1990.

MARCONDES, M. J. A. Cidade e Natureza. Proteção dos Mananciais e Exclusão Social. São Paulo: Studio Nobel/EDUSP/FAPESP, 1999.

O ANIVERSÁRIO de Cidade Dutra. O Interlagos, São Paulo, n.4, fev. 1965.

O ESTADO de S. Paulo, São Paulo, 4 fev. 1939.

PRADO JÚNIOR, C. A cidade de São Paulo: geografia e história. In: Evolução Política do Brasil e Outros Estudos. São Paulo: Brasiliense, 1966.

PREFEITURA DO MUNICÍPIO DE SÃO PAULO. Meu bairro, minha cidade: Você também faz parte dessa história. Cidade Dutra. São Paulo: 2004a.

PREFEITURA DO MUNICÍPIO DE SÃO PAULO. Meu bairro, minha cidade: Você também faz parte dessa história. Grajaú. Jardim Três Corações. São Paulo: 2004b.

PREFEITURA DO MUNICÍPIO DE SÃO PAULO. Meu bairro, minha cidade: Você também faz parte dessa história. Jardim São Luis. São Paulo: 2004c.

ROLNIK, R. A cidade e a lei: Legislação, política urbana e territórios na cidade de São Paulo. São Paulo: 
Studio Nobel/FAPESP, 1997.

ROLNIK, R. São Paulo, novo século: uma nova geografia? In: CAMPOS, C. M.; GAMA, L. H.; SACCHETTA, V. (Orgs.). São Paulo: metrópole em trânsito: percursos urbanos e culturais. São Paulo: Senac, 2004.

VILLAÇA, F. Elites, desigualdade e poder municipal. In: CAMPOS, C. M.; GAMA, L. H.; SACCHETTA, V. (Orgs.). São Paulo: metrópole em trânsito: percursos urbanos e culturais. São Paulo: Senac, 2004.

Recebido: 30 ago 2019

Aceito: 10 fev 2020

Comitê Editorial dos Cadernos Cedes/Coordenação deste número:

Alessandra Arce Hai e Ana Clara Bortoleto Nery 